\title{
Quantifying the emission changes and associated air quality impacts during the COVID-19 pandemic on the North China Plain: a response modeling study
}

\author{
Jia Xing ${ }^{1,2}$, Siwei $\mathbf{L i}^{3,4}$, Yueqi Jiang ${ }^{1,2}$, Shuxiao Wang ${ }^{1,2}$, Dian Ding ${ }^{1,2}$, Zhaoxin Dong ${ }^{1,2}$, Yun Zhu ${ }^{5}$, and Jiming Hao ${ }^{1,2}$ \\ ${ }^{1}$ State Key Joint Laboratory of Environmental Simulation and Pollution Control, School of Environment, \\ Tsinghua University, Beijing 100084, China \\ ${ }^{2}$ State Environmental Protection Key Laboratory of Sources and Control of Air Pollution Complex, Beijing 100084, China \\ ${ }^{3}$ School of Remote Sensing and Information Engineering, Wuhan University, Wuhan 430079, China \\ ${ }^{4}$ State Key Laboratory of Information Engineering in Surveying, Mapping and Remote Sensing, \\ Wuhan University, Wuhan 430079, China \\ ${ }^{5}$ College of Environment and Energy, South China University of Technology, \\ Guangzhou Higher Education Mega Center, Guangzhou 510006, China
}

Correspondence: Shuxiao Wang (shxwang@tsinghua.edu.cn) and Siwei Li (siwei.li@whu.edu.cn)

Received: 28 May 2020 - Discussion started: 14 July 2020

Revised: 3 October 2020 - Accepted: 15 October 2020 - Published: 25 November 2020

\begin{abstract}
Quantification of emission changes is a prerequisite for the assessment of control effectiveness in improving air quality. However, the traditional bottom-up method for characterizing emissions requires detailed investigation of emissions data (e.g., activity and other emission parameters) that usually takes months to perform and limits timely assessments. Here we propose a novel method to address this issue by using a response model that provides real-time estimation of emission changes based on air quality observations in combination with emission-concentration response functions derived from chemical transport modeling. We applied the new method to quantify the emission changes on the North China Plain (NCP) due to the COVID-19 pandemic shutdown, which overlapped the Spring Festival (also known as Chinese New Year) holiday. Results suggest that the anthropogenic emissions of $\mathrm{NO}_{2}, \mathrm{SO}_{2}$, volatile organic compound (VOC) and primary $\mathrm{PM}_{2.5}$ on the NCP were reduced by $51 \%, 28 \%, 67 \%$ and $63 \%$, respectively, due to the COVID-19 shutdown, indicating longer and stronger shutdown effects in 2020 compared to the previous Spring Festival holiday. The reductions of VOC and primary $\mathrm{PM}_{2.5}$ emissions are generally effective in reducing $\mathrm{O}_{3}$ and $\mathrm{PM}_{2.5}$ concentrations. However, such air quality improvements are largely offset by reductions in $\mathrm{NO}_{x}$ emissions. $\mathrm{NO}_{x}$ emission
\end{abstract}

reductions lead to increases in $\mathrm{O}_{3}$ and $\mathrm{PM}_{2.5}$ concentrations on the NCP due to the strongly VOC-limited conditions in winter. A strong $\mathrm{NH}_{3}$-rich condition is also suggested from the air quality response to the substantial $\mathrm{NO}_{x}$ emission reduction. Well-designed control strategies are recommended based on the air quality response associated with the unexpected emission changes during the COVID-19 period. In addition, our results demonstrate that the new response-based inversion model can well capture emission changes based on variations in ambient concentrations and thereby illustrate the great potential for improving the accuracy and efficiency of bottom-up emission inventory methods.

\section{Introduction}

Accurate estimation of anthropogenic emissions is crucial for atmospheric modeling studies and provides the basis for developing effective air pollution controls (Wang et al., 2010). A comprehensive emission inventory consists of the emission rates of primary particulate matter components and gaseous pollutants and precursors that are allocated over time and space. These inventories are usually developed using bottomup methods that gather detailed information about source ac- 
tivity and other emission parameters (Wang et al., 2011a; Xing et al., 2013; Li et al., 2017). The challenge is that such an investigation is costly and time-consuming, and therefore the latest emission inventories usually lag current conditions by a year or more. Many studies also apply a top-down methods to constrain emission estimates using satellite retrievals and modeling methods (Tang et al., 2013, 2019; Lu et al., 2015; Miyazaki et al., 2017; Cao et al., 2018; Zhang et al., 2018). In general, the traditional top-down inversion methods use four-dimensional data assimilation (MendozaDominguez and Russell, 2000) or Kalman filter methods (Hartley and Prinn, 1993) combined with sensitivity analysis of chemical transport modeling, like decoupled direct method in three dimensions (Napelenok et al., 2008) or adjoint method (Cao et al., 2018), to optimize the gap between the simulation and observation through adjusting the emission from an a priori estimate. The top-down inversion method can well reflect the change in emissions in a timely manner and thus efficiently estimate emissions at high spatial and temporal resolution to complement bottom-up inventories. Previous inversion studies have focused on individual pollutants that can be measured directly; however, studies are lacking that use top-down methods to estimate emissions of multiple pollutants, including those that cannot be directly measured, such as primary fine particular matter $\left(\mathrm{p}-\mathrm{PM}_{2.5}\right)$.

The ongoing coronavirus disease 2019 (COVID-19) pandemic has led to 4600 deaths in mainland China (by 24 May 2020, https://news.google.com/covid19/, last access: 24 May 2020) and has resulted in a dramatic curtailment of routine economic and social activities. The shutdown of human activities during the COVID-19 pandemic has led to reduced pollutant emissions and possibly improved air quality (Shi and Brasseur, 2020; Wang et al., 2020). Yet according to ambient concentration measurements, heavy $\mathrm{PM}_{2.5}$ pollution still occurred during the COVID-19 period, and formation of secondary pollutants was actually enhanced in China (Li et al., 2020; Huang et al., 2020). Some studies attributed pollution enhancements to atypical weather conditions that are favorable for air pollution formation (Wang and $\mathrm{Su}, 2020$ ). Meanwhile, the unexpected reduction of anthropogenic emissions due to the COVID-19 shutdown might vary significantly for different sectors and species. For example, emissions from domestic sources might have increased due to a greater demand for home heating and other essential consumptions during periods with stay-at-home orders in effect. Moreover, the coincidence of the COVID-19 shutdown and the Spring Festival in China resulted in large numbers of people confined to their rural or small-city hometowns, where consumption patterns differ greatly from their primary residence in megacities. Relative to previous years, both emissions and meteorological conditions varied simultaneously during the 2020 COVID-19 shutdown, and an accurate estimation of the changes in anthropogenic emissions accounting for meteorological variations is needed to characterize the impacts of COVID-19 on air quality.
Here we propose a novel inversion technique based on a multi-pollutant nonlinear response model to estimate the emission changes on the North China Plain (NCP) during the COVID-19 shutdown. Emission changes for the COVID19 period are calculated as the difference between emission estimates for actual conditions and hypothetical conditions assuming the shutdown did not occur. The hypothetical emissions are determined by combining top-down emission estimates from before and after the shutdown with estimates of the temporal variation in emissions from a bottom-up emission inventory. Additionally, we estimate the change in emissions associated with the Spring Festival holiday in 2019 to contrast with results for the combined Spring Festival holiday and COVID-19 shutdown in 2020. Finally, we evaluate the impacts on $\mathrm{PM}_{2.5}$ and $\mathrm{O}_{3}$ concentrations of the combined emission changes and for each emitted species to provide insights for the design of effective control strategies in the future.

\section{Methods}

\subsection{Response model to estimate the actual emissions from observed surface concentrations}

The principle of the new response-based inversion model (hereafter "the response model") is to adjust the assumed prior emissions such that concentration predictions match observations. Different from previous top-down methods that apply sensitivity based optimization, this study adopted emission-concentration response functions which provide real-time estimates of the concentrations under various emission scenarios. Therefore it can make the adjustment of emissions match with the observation more straightforwardly by avoiding the calculation of the sensitivities. Meanwhile, the natural linkage exists in air pollutants like $\mathrm{PM}_{2.5}$ and $\mathrm{O}_{3}$ since both pollutants have contributions from common precursors $\left(\mathrm{NO}_{x}\right.$ and volatile organic compound, VOC), similar atmospheric diffusion-advection transport, and chemical oxidation reactions. The advantage of the new method is its ability to represent the nonlinearity of $\mathrm{PM}_{2.5}$ and $\mathrm{O}_{3}$ response to the change in their precursor emissions. Thus, it can assimilate both pollutants simultaneously by keeping the natural linkage. In addition, to address the "ill-posedness" inversion problem, we took advantage of all available observations for multiple pollutants and constrained the adjustment of emissions at provincial scale rather than at each single grid cell. That means we only change total emissions of each province but keep spatial and temporal variation the same as that in the a priori emissions. Such a design makes the new method have a small sensitivity to the change of observation sites due to the use of prior knowledge of the spatial distribution of emissions, which is particularly useful for certain period when observations are not always available across the whole region. However, the new method has limited ability to as- 


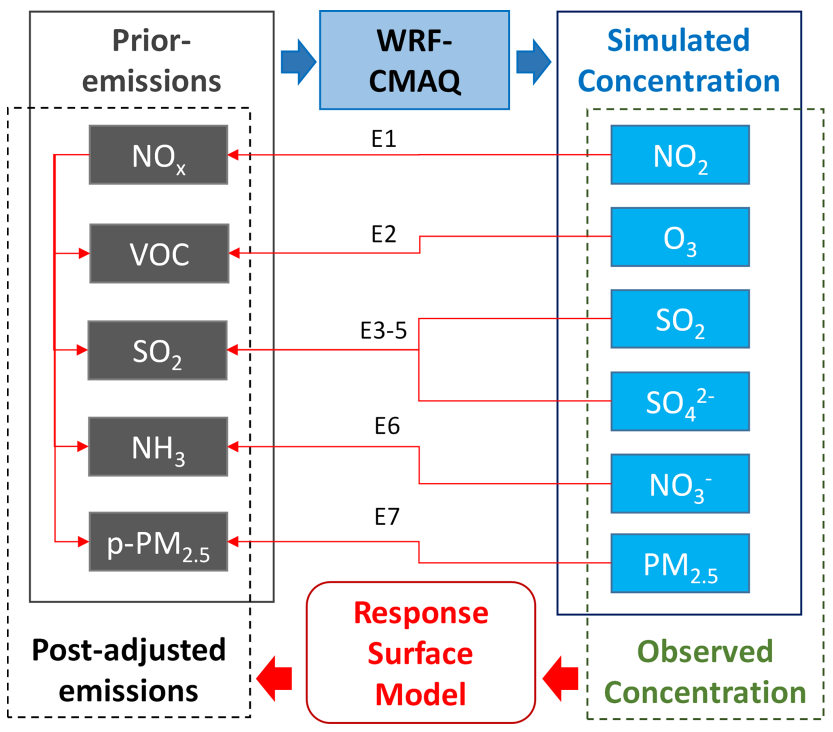

Figure 1. The response modeling framework for adjusting the emissions (Eqs. 1-7 are equations used to adjusted emissions, which are detailed in the text).

similate concentrations at the edge of the control region and may suffer uncertainties in the spatial and temporal variations which are unable to be adjusted by this method (Xing et al., 20201). Nevertheless, since the study mainly focuses on the relative change of total emissions over the NCP region due to the COVID-19 rather than improving the baseline emissions, our new method is thus more suitable to address such a specific purpose.

The core element of the inversion method is a nonlinear response surface model (RSM) that represents the emissionconcentration response functions. The framework of the response model is illustrated in Fig. 1. We conduct chemical transport model simulations using prior emissions to get the original simulated concentrations of six pollutants (i.e., $\mathrm{NO}_{2}$; $\mathrm{O}_{3} ; \mathrm{SO}_{2} ; \mathrm{PM}_{2.5} ;$ sulfate, $\mathrm{SO}_{4}^{2-}$; and nitrate, $\mathrm{NO}_{3}^{-}$), as well as the response functions derived from the RSM (Xing et al., 2011; Wang et al., 2011b; Xing et al., 2017, 2018). We then adjust the total emission ratio of five pollutants (i.e., $\mathrm{NO}_{2}$, VOC, $\mathrm{SO}_{2}, \mathrm{NH}_{3}$ and primary $\mathrm{PM}_{2.5}$ ) in five provinces of the NCP (i.e., Beijing, Tianjin, Hebei, Shandong and Henan) to estimate the updated simulated concentrations to match with the observations. Since the RSM was originally built based on the 3-D chemical transport model through multipleemission scenarios by changing total emissions at controlled regions, both local source and non-local transport and transformation have been considered in the assimilation.

Based on our previous knowledge of emissionconcentration response relationships, we first adjust $\mathrm{NO}_{x}$ emissions such that RSM predictions match $\mathrm{NO}_{2}$ observations (see Eq. 1), since $\mathrm{NO}_{2}$ concentrations have a strong linear relationship with $\mathrm{NO}_{x}$ emissions (Xing et al., 2017).
$E_{\mathrm{NO}_{x}}^{\prime}=r_{\mathrm{NO}_{x}} \times E_{\mathrm{NO}_{x}}^{*}=E_{\mathrm{NO}_{x}}^{*} \times \frac{C_{\mathrm{NO}_{2}}^{\mathrm{o}}}{C_{\mathrm{NO}_{2}}^{\mathrm{s}}}$,

where $E_{\mathrm{NO}_{x}}^{\prime}$ is the adjusted $\mathrm{NO}_{x}$ emissions; $E_{\mathrm{NO}_{x}}^{*}$ is the prior $\mathrm{NO}_{x}$ emissions; $r_{\mathrm{NO}_{x}}$ is the adjustment ratio for $\mathrm{NO}_{x}$ emissions; $C_{\mathrm{NO}_{2}}^{\mathrm{o}}$ is the observed $\mathrm{NO}_{2}$ concentrations; and $C_{\mathrm{NO}_{2}}^{\mathrm{s}}$ is the simulated $\mathrm{NO}_{2}$ concentrations.

Next, we adjust VOC emissions such that RSM predictions match observed $\mathrm{O}_{3}$ concentrations, since $\mathrm{O}_{3}$ concentrations are solely determined by VOC emissions after $\mathrm{NO}_{x}$ emissions are determined in the previous step. The adjusted VOC emission ratio (i.e., $r_{\mathrm{VOC}}=E_{\mathrm{VOC}}^{\prime} / E_{\mathrm{VOC}}^{*}$ ) is determined by solving the following equation:

$\Delta \mathrm{O}_{3}=\left(C_{\mathrm{O}_{3}}^{\mathrm{o}}-C_{\mathrm{O}_{3}}^{\mathrm{s}}\right)=\mathrm{RSM}_{\mathrm{O}_{3}}\left(r_{\mathrm{NO}_{x}}, r_{\mathrm{VOC}}\right)$,

where $E_{\mathrm{VOC}}^{\prime}$ is the adjusted VOC emissions; $E_{\mathrm{VOC}}^{*}$ is the prior VOC emissions; $\triangle \mathrm{O}_{3}$ is the difference between observed $\mathrm{O}_{3}$ concentrations $\left(\mathrm{C}_{\mathrm{O}_{3}}^{\mathrm{o}}\right)$ and simulated $\mathrm{O}_{3}$ concentrations $\left(C_{\mathrm{O}_{3}}^{\mathrm{s}}\right)$; and $\mathrm{RSM}_{\mathrm{O}_{3}}$ is the response function of $\mathrm{O}_{3}$ concentrations to $\mathrm{NO}_{x}$ and VOC emissions.

Although $\mathrm{SO}_{2}$ concentrations are linearly related to $\mathrm{SO}_{2}$ emissions, the chemical transport model overestimates $\mathrm{SO}_{2}$ concentrations and underestimates $\mathrm{SO}_{4}^{2-}$ concentrations due to large uncertainties in simulating the rapid conversion of $\mathrm{SO}_{2}$ to $\mathrm{SO}_{4}^{2-}$ during haze episodes (Zhang et al., 2019). To address this deficiency, we adjusted the $\mathrm{SO}_{2}$ emissions using the observed $\mathrm{SO}_{4}^{2-} / \mathrm{SO}_{2}$ ratio such that the $\mathrm{RSM}$ predictions matched both the observed $\mathrm{SO}_{2}$ and $\mathrm{SO}_{4}^{2-}$ concentrations. Since $\mathrm{SO}_{4}^{2-}$ concentrations are quite linearly related to $\mathrm{SO}_{2}$ emissions when $\mathrm{NH}_{3}$ emissions are at moderate levels (Wang et al., 2011b), we assume that the unaccounted for $\mathrm{SO}_{2}$-to- $\mathrm{SO}_{4}^{2-}$ conversion pathway contributes to differences in the observed and simulated $\mathrm{SO}_{4}^{2-} / \mathrm{SO}_{2}$ ratios. Under this assumption, simulated $\mathrm{SO}_{2}$ concentrations are overestimated by the same ratio $(\alpha)$ that secondary $\mathrm{SO}_{4}^{2-}\left(C_{\mathrm{s}-\mathrm{SO}_{4}}^{\mathrm{s}}\right)$ concentrations are underestimated (see Eqs. 3 and 4). The primary $\mathrm{SO}_{4}^{2-}$ concentration $\left(C_{\mathrm{p}-\mathrm{SO}_{4}}^{\mathrm{s}}\right)$ was removed from the total $\mathrm{SO}_{4}^{2-}$ concentration in these calculations, because primary $\mathrm{SO}_{4}^{2-}$ is directly emitted and not related to the conversion of $\mathrm{SO}_{2}$ to $\mathrm{SO}_{4}^{2-}$ (see Eq. 4).

$$
\begin{aligned}
& C_{\mathrm{SO}_{2}}^{\mathrm{o}}=\frac{1}{\alpha} \times r_{\mathrm{SO}_{2}} \times C_{\mathrm{SO}_{2}}^{\mathrm{s}} \\
& C_{\mathrm{SO}_{4}}^{\mathrm{o}}=\alpha \times r_{\mathrm{SO}_{2}} \times C_{\mathrm{s}-\mathrm{SO}_{4}}^{\mathrm{s}}+C_{\mathrm{p}-\mathrm{SO}_{4}}^{\mathrm{s}} \\
& \alpha=\left(\frac{C_{\mathrm{SO}_{2}}^{\mathrm{o}}}{C_{\mathrm{SO}_{4}}^{\mathrm{o}}-C_{\mathrm{p}-\mathrm{SO}_{4}}^{\mathrm{s}}} / \frac{C_{\mathrm{SO}_{2}}^{\mathrm{s}}}{C_{\mathrm{SO}_{4}}^{\mathrm{s}}}\right)^{1 / 2}
\end{aligned}
$$

The adjusted $\mathrm{SO}_{2}$ emission ratio $\left(r_{\mathrm{SO}_{2}}\right)$ is estimated by taking the ratio of observed $\mathrm{SO}_{2}\left(C_{\mathrm{SO}_{2}}^{\mathrm{o}}\right)$ to simulated $\mathrm{SO}_{2}\left(C_{\mathrm{SO}_{2}}^{\mathrm{s}}\right)$ multiplied by $\alpha$, which accounts for the model deficiency in 
simulating the rapid conversion of $\mathrm{SO}_{2}$ to $\mathrm{SO}_{4}^{2-}$. For simplification, here we estimate the $\alpha$ value at a domain and temporal averaged level (i.e., identical across the space and time), though such a ratio might vary with time and space. Also the primary $\mathrm{SO}_{4}$ concentrations were assumed to be correct. The $\alpha$ is smaller than 1 because the observed $\mathrm{SO}_{4}^{2-} / \mathrm{SO}_{2}$ is usually greater than the simulation. The inclusion of the $\alpha$ may help the response model avoid the underestimation of $\mathrm{SO}_{2}$ emissions.

Using the adjusted $\mathrm{NO}_{x}$, VOC and $\mathrm{SO}_{2}$ emissions from previous steps, we next adjusted $\mathrm{NH}_{3}$ emissions such that RSM predictions of $\mathrm{NO}_{3}^{-}$concentrations matched observations:

$$
\begin{aligned}
\Delta \mathrm{NO}_{3}^{-} & =\left(C_{\mathrm{NO}_{3}}^{\mathrm{o}}-C_{\mathrm{NO}_{3}}^{\mathrm{s}}\right) \\
& =\operatorname{RSM}_{\mathrm{NO}_{3}}\left(r_{\mathrm{NO}_{x}}, r_{\mathrm{VOC}}, r_{\mathrm{SO}_{2}}, r_{\mathrm{NH}_{3}}\right),
\end{aligned}
$$

where $r_{\mathrm{NH}_{3}}=E_{\mathrm{NH}_{3}}^{\prime} / E_{\mathrm{NH}_{3}}^{*}, E_{\mathrm{NH}_{3}}^{\prime}$ is the adjusted $\mathrm{NH}_{3}$ emissions, and $E_{\mathrm{NH}_{3}}^{*}$ is the prior $\mathrm{NH}_{3}$ emissions.

After updating the emissions of the four gaseous precursors, the secondary portion of $\mathrm{PM}_{2.5}$ was correspondingly determined, including the secondary organic aerosol contributed by the VOC emissions. Finally, the primary $\mathrm{PM}_{2.5}$ emissions were adjusted to provide agreement between simulated and observed total $\mathrm{PM}_{2.5}$ concentrations:

$$
\begin{aligned}
\Delta \mathrm{PM}_{2.5} & =\left(C_{\mathrm{PM}_{2.5}}^{\mathrm{o}}-C_{\mathrm{PM}_{2.5}}^{\mathrm{s}}\right) \\
& =\operatorname{RSM}_{\mathrm{PM}_{2.5}}\left(r_{\mathrm{NO}_{x}}, r_{\mathrm{VOC}}, r_{\mathrm{SO}_{2}}, r_{\mathrm{NH}_{3}}, r_{\mathrm{p}-\mathrm{PM}_{2.5}}\right),
\end{aligned}
$$

where $r_{\mathrm{p}-\mathrm{PM}_{2.5}}=E_{\mathrm{p}-\mathrm{PM}_{2.5}}^{\prime} / E_{\mathrm{p}-\mathrm{PM}_{2.5}}^{*}, E_{\mathrm{p}-\mathrm{PM}_{2.5}}^{\prime}$ is the adjusted primary $\mathrm{PM}_{2.5}$ emissions, and $E_{\mathrm{p}-\mathrm{PM}_{2.5}}^{*}$ is the prior primary $\mathrm{PM}_{2.5}$ emissions.

The prior emissions used here were based on a bottomup inventory developed for 2017. Since our study focuses on periods in 2019 and 2020, we first use the response model to adjust the 2017 emission inventory to match the observations during two study periods. The first study period was defined as 1 January-31 March 2019 to capture changes in activity due the Spring Festival. The second study period was defined as the same 3 months in 2020 to capture the COVID19 shutdown on the NCP, which overlapped the 2020 Spring Festival holiday. We defined three subperiods within the 3 months in each year as pre-shutdown (Period 1), shutdown (Period 2) and post-shutdown (Period 3). The days selected for subperiods differed in 2019 and 2020 due to differences in the dates and lengths of the shutdowns. For 2019, we defined Period 1 as 1-29 January (29d); Period 2 as 30 January18 February (20 d), which is a week before and after the 2019 lunar New Year holidays; and Period 3 as 19 February31 March (41 d). For 2020, we defined Period 1 as 1-22 January (22 d); Period 2 as 23 January-5 March (33 d), which is from the date that Chinese authorities began targeting transportation shutdowns until all human activities began recovering in early March (http://www.gov.cn/index.htm, last access: 24 May 2020); and Period 3 as 6-31 March (26d). The stage-averaged emissions are corrected by applying a unified change ratio to each pollutant emission at each stage, and the temporal variations such as hourly profiles are kept the same as those in the a priori estimates.

The RSM was developed using ambient concentrations from simulations with the Community Multiscale Air Quality (CMAQ, version 5.2.1) model, which incorporated meteorological fields from the Weather Research and Forecasting (WRF, version 3.8) model. The WRF-CMAQ system was configured as in our previous studies, and model performance for meteorological variables and pollutant concentrations was evaluated (Ding et al., 2019). The RSM was developed following the same design as our previous study (Xing et al., 2018), in which the polynomial response functions for $\mathrm{O}_{3}, \mathrm{PM}_{2.5}$ and $\mathrm{PM}_{2.5}$ components were fitted by 40 bruteforce CMAQ simulations. Specifically, deep-learning technology was used to fit response surfaces for the 3 months in 2019 and 2020 using CMAQ simulations for baseline and zero-out emissions conditions (see Fig. 2 in Xing et al., 2020b). The response surfaces were developed using yearspecific meteorology based on WRF simulations to account for differences in meteorological conditions between 2019 and 2020.

Measurements of ambient concentrations of $\mathrm{NO}_{2}, \mathrm{SO}_{2}$, $\mathrm{O}_{3}$ and $\mathrm{PM}_{2.5}$ were obtained from the China National Environmental Monitoring Centre (http://106.37.208.233:20035/, last access: 24 May 2020). Measurements of $\mathrm{PM}_{2.5}$ chemical components, including $\mathrm{NO}_{3}^{-}$and $\mathrm{SO}_{4}^{2-}$, were provided by the urban PM data analysis platform in the $2+26$ cities of Beijing-Tianjin-Hebei and surrounding regions (http://106. 37.181.120:9011/bfs, last access: 24 May 2020). All monitoring data were given as hourly averaged concentrations at the monitoring sites shown in Fig. 2. As in our previous RSM studies, daily daytime $\mathrm{O}_{3}$ concentrations were analyzed based on afternoon averages (12:00-18:00 local time), and $\mathrm{PM}_{2.5}$ concentrations were based on daily $24 \mathrm{~h}$ averages (Xing et al., 2018). Only data at monitoring sites that covered the $90 \%$ of entire period are considered. Since the monitors sample pollutants at discrete locations and measurements are not available for all days at all sites, provincial average concentrations were used to facilitate adjustments domain-wide for all days in each study period. The provincial average concentrations were calculated using spatially and temporally matched simulated and observed values.

\subsection{Hypothetical emissions without shutdown effects}

The actual emissions can be derived using observed concentrations and the response model. However, hypothetical emissions under the assumption of no shutdown effects are also needed to estimate the changes in emissions due to the 2019 and 2020 shutdowns. We estimate the hypothetical emissions using the temporal profiles of sectoral emissions from the bottom-up inventory in combination with the derived (actual) emissions for the pre- and post-shutdown 


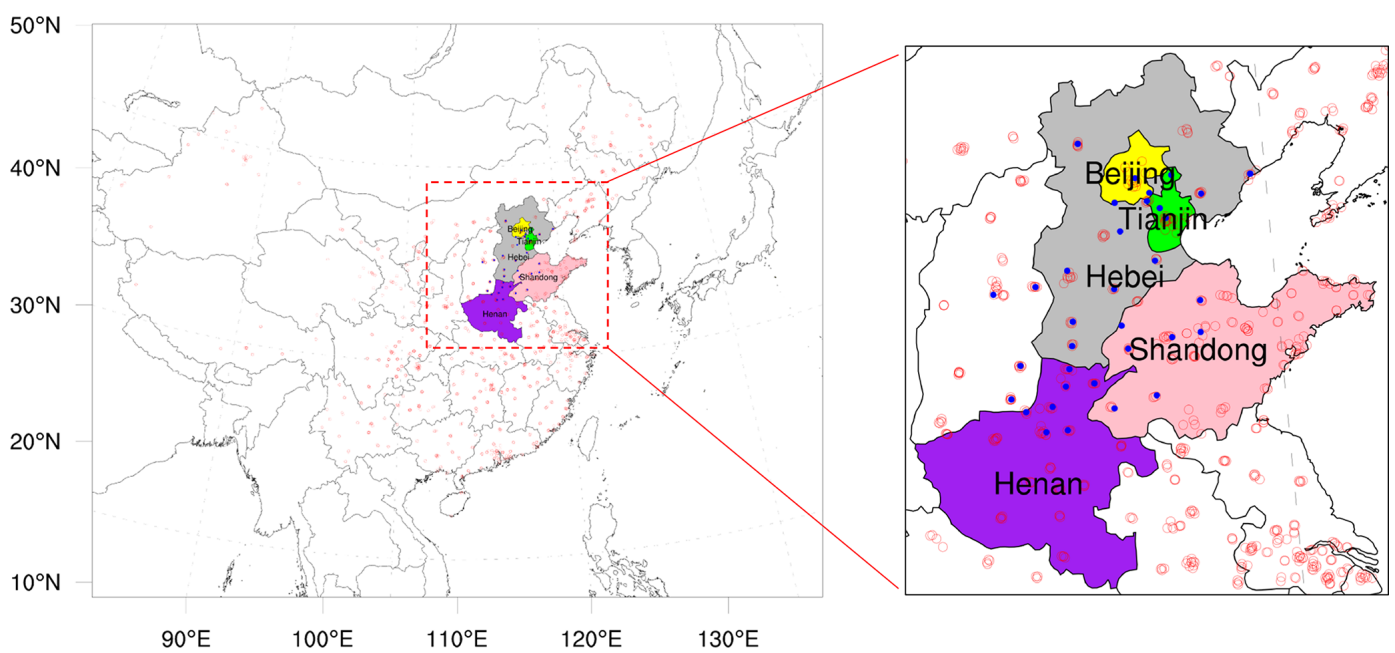

Figure 2. Simulation domain and location of observation sites (colored area: five provinces of the North China Plain; red dots: surface monitor sites for $\mathrm{NO}_{2}, \mathrm{SO}_{2}, \mathrm{O}_{3}$ and $\mathrm{PM}_{2.5}$; blue dots: monitor sites for $\mathrm{PM}_{2.5}$ chemical components).

periods. We assume that the Spring Festival shutdowns in 2019 have negligible influence on emissions during the periods before and after the shutdown (i.e., Period 1 and Period 3, respectively), while the COVID-19 pandemic in 2020 might have had lag effects after the shutdown due to reduced economic activity or relaxed pollutant controls. However, we concentrate our analysis of COVID-19 impacts on emissions and air quality in the official shutdown period only (Period 2). The hypothetical no-shutdown emissions for Period 2 (noted as Period $2 \mathrm{H}$ ) are estimated using ratios of emissions for Period 2 and Period 1 and 3 based on the temporal profile (i.e., reflect the monthly variation across a year) of the bottom-up inventory which only reflects the natural evolution of emissions across a year for each sector. It is roughly close to the temporally averaged ratios between Periods 1 and 3 , and the exact values depend on the number of days covering in each period. This approach develops hypothetical emissions following the typical variation in emissions without shutdown effects. Note that we use the temporal profile to determine the change in Period 2 emissions relative to Period 1 and 3, and so emissions from both Period 1 and 3 are needed to estimate Period $2 \mathrm{H}$ emissions.

The emission changes due to the COVID-19 shutdown can be estimated by taking the difference of emissions in Period 2, derived from the response model, and emissions in Period $2 \mathrm{H}$, estimated from emissions in Period 1 and 3 using the temporal profile of bottom-up sectoral emissions. The impacts of emission changes during the COVID-19 shutdown on $\mathrm{PM}_{2.5}$ and $\mathrm{O}_{3}$ concentrations are then estimated with the RSM. In addition to the combined impacts of emission changes from multiple species, we estimate the impacts of individual pollutant emissions on $\mathrm{PM}_{2.5}$ and $\mathrm{O}_{3}$. Due to the nonlinearity of emission-concentration response functions, the impacts of individual pollutant emissions can vary significantly when other pollutant emissions are changing si- multaneously (Xing et al., 2018). To simplify the evaluation, we define an incremental method for analyzing the individual pollutant impacts in this study by adding incremental changes in pollutant emissions to the previous simulation in the following order: $\mathrm{NO}_{x}, \mathrm{VOC}, \mathrm{NH}_{3}, \mathrm{SO}_{2}$ and primary $\mathrm{PM}_{2.5}$, as described in Table 1. The impacts of individual pollutant emissions on $\mathrm{O}_{3}$ and $\mathrm{PM}_{2.5}$ concentrations are then estimated from the difference between the incrementally adjusted simulation and the previous one. Note that this approach is an approximation, and the impacts of individual pollutants could change if a different order is used.

\section{Results}

\subsection{Emission changes due to the shutdown}

Using the response model, the daily emissions of $\mathrm{NO}_{x}$, VOC, $\mathrm{NH}_{3}, \mathrm{SO}_{2}$ and primary $\mathrm{PM}_{2.5}$ on the $\mathrm{NCP}$ are estimated for three periods in 2019 and 2020, as summarized in Fig. 3 and detailed in Table 2 by provinces.

For Period 1 before the activity disruptions, the emissions of $\mathrm{NO}_{x}, \mathrm{SO}_{2}$ and VOC on the NCP decreased by $11 \%, 25 \%$ and $8 \%$ between 2019 and 2020, respectively. These reductions reflect the progress of air pollution controls between 2019 and 2020 and demonstrate the ability of the model to capture emission changes from routine air pollution control actions. The $\mathrm{p}-\mathrm{PM}_{2.5}$ emissions also significantly decreased in Beijing-Tianjin-Hebei provinces but increased in Shandong and Henan. The $\mathrm{NH}_{3}$ emissions did not change during this 2-year period, since $\mathrm{NH}_{3}$ is not considered in current policies.

Activity reductions occurred in Period 2 in both 2019 and 2020, although the shutdown due the Spring Festival in 2019 is much shorter than the COVID-19 shutdown in 2020. The 
Table 1. Sensitivity analysis for quantifying the impacts of individual pollutant emission changes on air quality.

\begin{tabular}{|c|c|c|c|}
\hline No. & Emission & Objective & Noted \\
\hline Sim-1 & $\begin{array}{l}\text { All pollutants are used as the hypothetical emis- } \\
\text { sions of Period } 2 \mathrm{H}\end{array}$ & $\begin{array}{l}\text { To estimate the hypothetical concentrations } \\
\text { without COVID impacts }\end{array}$ & oSIM \\
\hline Sim-2 & $\begin{array}{l}\text { Same as Sim-1 except } \mathrm{NO}_{x} \text { emissions are up- } \\
\text { dated to actual emissions in Period } 2\end{array}$ & $\begin{array}{l}\text { To estimate the impacts of } \mathrm{NO}_{x} \text { emission } \\
\text { changes on } \mathrm{O}_{3} \text { and } \mathrm{PM}_{2.5} \text { based on the differ- } \\
\text { ence between Sim- } 2 \text { and Sim- } 1\end{array}$ & $\Delta \mathrm{NO}_{x}$ \\
\hline Sim-3 & $\begin{array}{l}\text { Same as Sim-2 except VOC emissions are up- } \\
\text { dated to actual emissions in Period } 2\end{array}$ & $\begin{array}{l}\text { To estimate the impacts of VOC emission } \\
\text { changes on } \mathrm{O}_{3} \text { and } \mathrm{PM}_{2.5} \text { based on the differ- } \\
\text { ence between Sim- } 3 \text { and Sim- } 2\end{array}$ & $\triangle \mathrm{VOC}$ \\
\hline Sim-4 & $\begin{array}{l}\text { Same as Sim- } 3 \text { except } \mathrm{NH}_{3} \text { emissions are up- } \\
\text { dated to actual emissions in Period } 2\end{array}$ & $\begin{array}{l}\text { To estimate the impacts of } \mathrm{NH}_{3} \text { emission } \\
\text { changes on } \mathrm{PM}_{2.5} \text { based on the difference be- } \\
\text { tween Sim- } 4 \text { and Sim- } 3\end{array}$ & $\Delta \mathrm{NH}_{3}$ \\
\hline Sim-5 & $\begin{array}{l}\text { Same as } \mathrm{Sim}-4 \text { except } \mathrm{SO}_{2} \text { emissions are up- } \\
\text { dated to actual emissions in Period } 2\end{array}$ & $\begin{array}{l}\text { To estimate the impacts of } \mathrm{SO}_{2} \text { emission } \\
\text { changes on } \mathrm{PM}_{2.5} \text { based on the difference be- } \\
\text { tween Sim- } 5 \text { and Sim- } 4\end{array}$ & $\Delta \mathrm{SO}_{2}$ \\
\hline Sim-6 & $\begin{array}{l}\text { Same as Sim- } 5 \text { except primary } \mathrm{PM}_{2.5} \text { emissions } \\
\text { are updated to actual emissions in Period } 2\end{array}$ & $\begin{array}{l}\text { To estimate the impacts of primary } \mathrm{PM}_{2.5} \text { emis- } \\
\text { sion changes on } \mathrm{PM}_{2.5} \text { based on the difference } \\
\text { between Sim- } 6 \text { and Sim- } 5\end{array}$ & $\Delta \mathrm{p}-\mathrm{PM}_{2.5}$ \\
\hline
\end{tabular}

Table 2. Daily emissions of five pollutants in NCP provinces based on the response model (unit: kt d ${ }^{-1}$ ). p- $\mathrm{PM}_{2.5}: \mathrm{primary}^{\mathrm{PM}} 2.5$.

\begin{tabular}{|c|c|c|c|c|c|c|c|c|c|c|c|c|c|c|c|}
\hline \multirow[t]{2}{*}{2019} & \multicolumn{5}{|c|}{ Period 1 ( 29 d, 1 Jan to 29 Jan) } & \multicolumn{5}{|c|}{ Period $2(20 \mathrm{~d}, 30 \mathrm{Jan}$ to $18 \mathrm{Feb})$} & \multicolumn{5}{|c|}{ Period 3 (41 d, 19 Feb to 31 Mar) } \\
\hline & $\mathrm{NO}_{x}$ & $\mathrm{SO}_{2}$ & $\mathrm{NH}_{3}$ & VOC & $\mathrm{p}-\mathrm{PM}_{2.5}$ & $\mathrm{NO}_{x}$ & $\mathrm{SO}_{2}$ & $\mathrm{NH}_{3}$ & VOC & $\mathrm{p}-\mathrm{PM}_{2.5}$ & $\mathrm{NO}_{x}$ & $\mathrm{SO}_{2}$ & $\mathrm{NH}_{3}$ & VOC & $\mathrm{p}-\mathrm{PM}_{2.5}$ \\
\hline Beijing & 0.49 & 0.07 & 0.20 & 0.69 & 0.12 & 0.26 & 0.05 & 0.19 & 0.20 & 0.01 & 0.48 & 0.05 & 0.23 & 0.94 & 0.16 \\
\hline Hebei & 5.64 & 2.01 & 1.18 & 3.67 & 1.97 & 3.47 & 1.62 & 1.27 & 1.43 & 1.51 & 5.95 & 1.90 & 2.77 & 6.26 & 1.92 \\
\hline Shandong & 7.35 & 3.21 & 1.34 & 8.58 & 0.76 & 4.45 & 2.88 & 1.52 & 2.41 & 0.88 & 6.90 & 3.45 & 3.54 & 9.59 & 1.19 \\
\hline Henan & 5.34 & 1.49 & 1.31 & 4.08 & 1.54 & 3.04 & 1.31 & 1.74 & 0.71 & 1.84 & 4.46 & 1.84 & 4.27 & 4.46 & 1.33 \\
\hline 2020 & $\mathrm{NO}_{x}$ & $\mathrm{SO}_{2}$ & $\mathrm{NH}_{3}$ & VOC & $\mathrm{p}-\mathrm{PM}_{2.5}$ & $\mathrm{NO}_{x}$ & $\mathrm{SO}_{2}$ & $\mathrm{NH}_{3}$ & VOC & $\mathrm{p}-\mathrm{PM}_{2.5}$ & $\mathrm{NO}_{x}$ & $\mathrm{SO}_{2}$ & $\mathrm{NH}_{3}$ & VOC & $\mathrm{p}-\mathrm{PM}_{2.5}$ \\
\hline Beijing & 0.38 & 0.04 & 0.20 & 0.65 & 0.01 & 0.23 & 0.03 & 0.20 & 0.27 & 0.01 & 0.28 & 0.04 & 0.24 & 0.70 & 0.09 \\
\hline Tianjin & 0.64 & 0.12 & 0.15 & 0.87 & 0.02 & 0.44 & 0.12 & 0.17 & 0.44 & 0.03 & 0.71 & 0.18 & 0.30 & 1.20 & 0.10 \\
\hline Hebei & 5.28 & 1.34 & 1.18 & 3.12 & 1.73 & 3.15 & 1.16 & 1.54 & 1.92 & 0.81 & 4.97 & 1.67 & 3.49 & 4.72 & 0.75 \\
\hline Shandong & 6.57 & 2.55 & 1.34 & 8.02 & 0.85 & 3.28 & 2.25 & 1.88 & 2.44 & 0.16 & 5.87 & 3.57 & 4.52 & 8.44 & 0.14 \\
\hline
\end{tabular}

emissions of $\mathrm{NO}_{x}, \mathrm{SO}_{2}$ and $\mathrm{p}-\mathrm{PM}_{2.5}$ in Period 2 in 2020 are substantially lower than in $2019(29 \%, 22 \%$ and $73 \%$, respectively). The decreases of $\mathrm{NO}_{x}$ and $\mathrm{p}-\mathrm{PM}_{2.5}$ for Period 2 between 2019 and 2020 are larger than the decreases for Period 1, which did not experience shutdowns. Such results suggest that the COVID-19 shutdown in 2020 had longer and stronger impacts on emissions than the Spring Festival shutdown in 2019. Interestingly, emissions of $\mathrm{NH}_{3}$ and VOC increased significantly (by $5 \%$ and $14 \%$ ) from 2019 to 2020 in Period 2. These changes are likely due to the temporal variations of emissions of both species, which are enhanced in warmer months due to stronger evaporation. Period 2 in 2020 extended farther into the spring (until early March) than Period 2 in 2019 and thus led to increased evaporative emissions of $\mathrm{NH}_{3}$ and VOC. These results also demonstrate the importance of developing emissions with high temporal resolution.

For Period 3 after the shutdown, the decreases of $\mathrm{NO}_{x}$ emissions $(14 \%)$ are similar to those in Period $1(11 \%)$, indicating the recovery of the activity. However, the emissions of VOC and $\mathrm{p}-\mathrm{PM}_{2.5}$ are much lower in Period 3 in 2020 compared to that in 2019, suggesting lag effects af- 

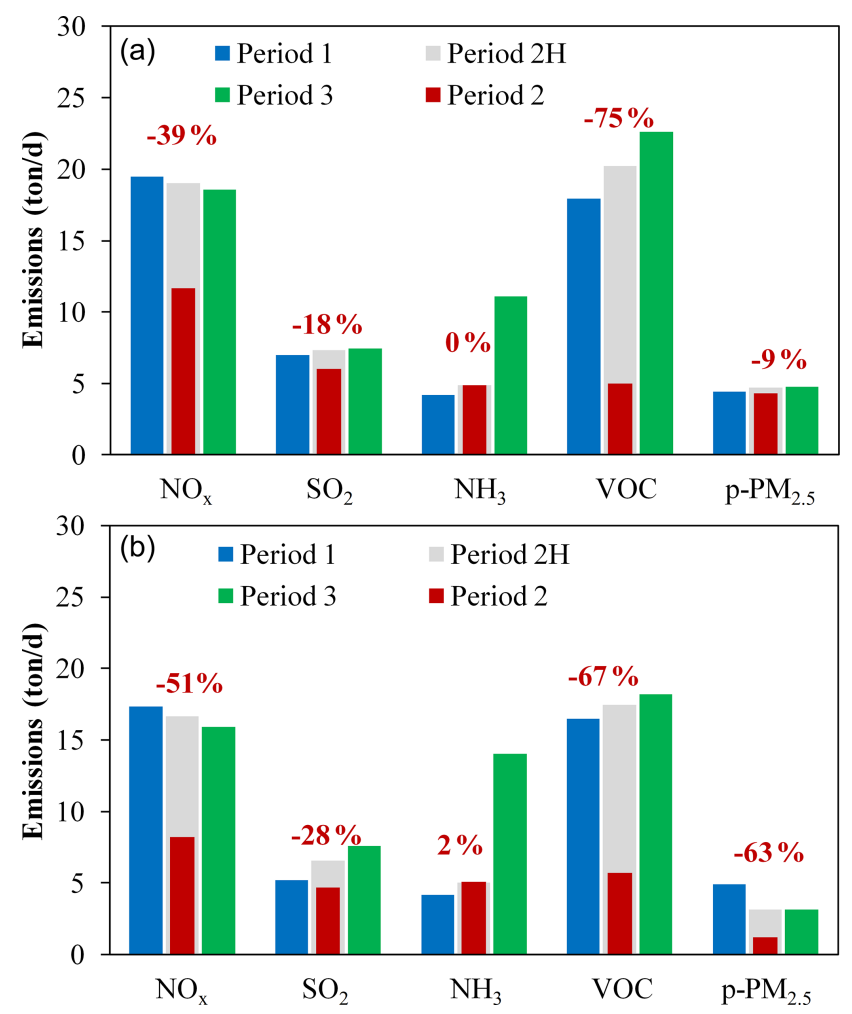

Figure 3. Daily emissions during pre-shutdown (Period 1, blue), shutdown (Period 2, red) and post-shutdown (Period 3, green) periods in 2019 and 2020. Period 2H (grey) is the hypothetical emissions without reduced activity during the 2019 holiday or 2020 COVID-19 shutdown; the red number indicates the percent change in emissions due to the shutdown in Period 2.

ter the COVID-19 shutdown in 2020. In contrast, the small increases of $\mathrm{SO}_{2}$ emissions in $2020(2 \%)$ might be associated with the extended central heating activity through the end of March in 2020, compared with mid-March in 2019. Higher $\mathrm{NH}_{3}$ emissions in Period 3 in 2020 than 2019 are also due to the larger coverage of warm days in Period 3 of 2020. $\mathrm{NH}_{3}$ emissions show the strongest monthly variations among all pollutants (Fig. 3). Similarly, increases in VOC emissions are also driven by the change of meteorological conditions (i.e., the higher air temperature in March leads to a larger evaporative emissions), though the growth of VOC emissions from Period 1 to Period 3 is reduced by the COVID-19 shutdown in 2020. Such results also demonstrate that the response model can capture the temporal variations of emissions even in cases where emissions are strongly coupled with meteorological conditions.

The influence of the shutdown is estimated as the difference in emissions between Period 2H (hypothetical emissions without shutdown effects) and Period 2 (actual emissions), as shown in Fig. 3 (grey and red bars respectively) and detailed in Table 3 by NCP province. Due to the COVID-19 shutdown in 2020, emissions of $\mathrm{NO}_{x}$, VOC and $\mathrm{PM}_{2.5}$ de- creased substantially by $51 \%, 67 \%$ and $63 \%$, respectively. $\mathrm{SO}_{2}$ emissions also decreased by $28 \%$, while $\mathrm{NH}_{3}$ emissions experienced very small increases $(+2 \%)$ which might be associated with increased activities in rural areas (e.g., potential $\mathrm{NH}_{3}$ emission sources like stool burning) as many people relocated from megacities to small towns or the countryside. Compared to the effects of the Spring Festival in 2019, the COVID-19 shutdown led to greater reductions in $\mathrm{NO}_{x}, \mathrm{SO}_{2}$ and $\mathrm{PM}_{2.5}$ emissions. The smaller VOC reduction in 2020 compared to 2019 might be due to the difference in temporal coverage of Period 2 in the 2 years (i.e., there were more warm days in Period 2 in 2020). Note that the hypothetical emissions in Period $2 \mathrm{H}$ are estimated based on the assumption of no shutdown effects in both Period 1 and Period 3. Therefore the reduction of those pollutant emissions in 2020 might be even larger considering the lag effects of COVID19.

\subsection{The shutdown effects on ambient concentrations}

Using the RSM, we predicted concentrations based on the updated emissions from the response-based inversion model. In general, the simulated concentrations based on the adjusted emissions matched well with the observed concentrations, as shown in Fig. 4 for NCP averages and detailed by province in Figs. S1-S12 in the Supplement. More important, during the shutdown period in both years, the simulations using adjusted emissions without considering shutdown influences significantly overestimate the $\mathrm{NO}_{2}$ concentrations in 2019 and 2020 by $61 \%$ and $81 \%$, respectively. The high biases in 2019 and 2020 are reduced to within $1 \%$ in the simulation with consideration of shutdown effects (Fig. 4a). To evaluate the performance of assimilation, we also conducted the cross validation by using $50 \%$ observation sites for estimating the emission ratio to be applied on the remaining $50 \%$ of observation sites for testing. The performance of cross validation is examined, suggesting quite similar results with that using all observation sites as shown in Fig. 4. The estimated percent changes in emissions due to the shutdown in Period 2 from cross validation are also close to that using all observation sites, as shown in Fig. S13.

The results for $\mathrm{O}_{3}$ are quite interesting, as simulated $\mathrm{O}_{3}$ concentrations are close to observations in both simulations with and without consideration of shutdown influences (Fig. 4b). The apparent insensitivity of $\mathrm{O}_{3}$ concentrations to emission changes during the shutdown can be explained by the opposite response of $\mathrm{O}_{3}$ to its two precursors, $\mathrm{NO}_{x}$ and VOC. In Fig. 5a, we compare the response of $\mathrm{O}_{3}$ concentrations for two $\mathrm{NO}_{x}$ and VOC emission change pathways starting from the hypothetical emissions for no-shutdown conditions (black symbol in Fig. 5a). Since $\mathrm{NO}_{x}$ emissions clearly decreased due to the shutdown, the $\mathrm{O}_{3}$ concentrations would increase if VOC emissions remained constant (following the green line to the green symbol in Fig. 5a). Yet the simulation without consideration of VOC emission changes would re- 
Table 3. The shutdown impacts on the emission of five pollutants in NCP provinces. p- $\mathrm{PM}_{2.5}$ : primary $\mathrm{PM}_{2.5}$.

\begin{tabular}{|c|c|c|c|c|c|c|c|c|c|c|}
\hline \multirow[t]{2}{*}{2019} & \multicolumn{2}{|c|}{$\mathrm{NO}_{x}$} & \multicolumn{2}{|c|}{$\mathrm{SO}_{2}$} & \multicolumn{2}{|c|}{$\mathrm{NH}_{3}$} & \multicolumn{2}{|c|}{ VOC } & \multicolumn{2}{|c|}{$\mathrm{p}-\mathrm{PM}_{2.5}$} \\
\hline & $\mathrm{ktd}^{-1}$ & $\%$ & $\mathrm{ktd}^{-1}$ & $\%$ & $\mathrm{ktd}^{-1}$ & $\%$ & $\mathrm{ktd}^{-1}$ & $\%$ & $\mathrm{ktd}^{-1}$ & $\%$ \\
\hline Beijing & -0.23 & $-47 \%$ & -0.01 & $-21 \%$ & 0.00 & $0 \%$ & -0.56 & $-73 \%$ & -0.15 & $-93 \%$ \\
\hline Tianjin & -0.30 & $-41 \%$ & -0.02 & $-10 \%$ & 0.00 & $0 \%$ & -0.95 & $-80 \%$ & -0.07 & $-62 \%$ \\
\hline Hebei & -2.33 & $-40 \%$ & -0.34 & $-17 \%$ & 0.00 & $0 \%$ & -3.54 & $-71 \%$ & -0.51 & $-25 \%$ \\
\hline Shandong & -2.67 & $-37 \%$ & -0.46 & $-14 \%$ & 0.00 & $0 \%$ & -6.78 & $-74 \%$ & -0.10 & $-10 \%$ \\
\hline Henan & -1.85 & $-38 \%$ & -0.48 & $-27 \%$ & 0.00 & $0 \%$ & -3.39 & $-83 \%$ & 0.39 & $27 \%$ \\
\hline $\mathrm{NCP}$ & -7.38 & $-39 \%$ & -1.31 & $-18 \%$ & 0.00 & $0 \%$ & -15.23 & $-75 \%$ & -0.43 & $-9 \%$ \\
\hline \multirow[t]{2}{*}{2020} & \multicolumn{2}{|c|}{$\mathrm{NO}_{x}$} & \multicolumn{2}{|c|}{$\mathrm{SO}_{2}$} & \multicolumn{2}{|c|}{$\mathrm{NH}_{3}$} & \multicolumn{2}{|c|}{ VOC } & \multicolumn{2}{|c|}{$\mathrm{p}-\mathrm{PM}_{2.5}$} \\
\hline & $\mathrm{ktd}^{-1}$ & $\%$ & $\mathrm{ktd}^{-1}$ & $\%$ & $\mathrm{ktd}^{-1}$ & $\%$ & $\mathrm{ktd}^{-1}$ & $\%$ & $\mathrm{ktd}^{-1}$ & $\%$ \\
\hline Beijing & -0.10 & $-30 \%$ & -0.01 & $-18 \%$ & 0.00 & $2 \%$ & -0.39 & $-59 \%$ & -0.07 & $-85 \%$ \\
\hline Tianjin & -0.24 & $-35 \%$ & -0.03 & $-18 \%$ & 0.00 & $2 \%$ & -0.60 & $-58 \%$ & -0.04 & $-59 \%$ \\
\hline Hebei & -1.98 & $-39 \%$ & -0.31 & $-21 \%$ & 0.03 & $2 \%$ & -1.89 & $-50 \%$ & -0.43 & $-35 \%$ \\
\hline Shandong & -2.95 & $-47 \%$ & -0.75 & $-25 \%$ & 0.04 & $2 \%$ & -5.80 & $-70 \%$ & -0.31 & $-66 \%$ \\
\hline Henan & -3.16 & $-74 \%$ & -0.76 & $-40 \%$ & 0.03 & $2 \%$ & -3.10 & $-83 \%$ & -1.10 & $-87 \%$ \\
\hline $\mathrm{NCP}$ & -8.42 & $-51 \%$ & -1.85 & $-28 \%$ & 0.10 & $2 \%$ & -11.77 & $-67 \%$ & -1.95 & $-63 \%$ \\
\hline
\end{tabular}

sult in a high bias of simulated $\mathrm{O}_{3}$ concentrations compared to the observations by $49 \%$ in 2019 and $29 \%$ in 2020 . The low observed $\mathrm{O}_{3}$ concentrations during Period 2 in both years indicates that VOC emission reductions must have occurred to maintain the suppressed $\mathrm{O}_{3}$ level (following the red line to the red symbol in Fig. 5a). Consistent with this interpretation, the simulated $\mathrm{O}_{3}$ concentrations agree well with observations (e.g., normalized mean bias, $\mathrm{NMB}<3 \%$ ) when both $\mathrm{NO}_{x}$ and VOC emission reductions are represented.

The substantial reduction of $\mathrm{NO}_{x}$ emissions also resulted in noticeable decreases in $\mathrm{NO}_{3}^{-}$concentrations (black and green lines in Fig. 4c). However, the low bias in $\mathrm{NO}_{3}^{-}$predictions cannot be readily mitigated by adjusting the $\mathrm{NH}_{3}$ emissions, because the substantial decreases in $\mathrm{NO}_{x}$ emissions associated with the shutdown result in strong $\mathrm{NH}_{3}$-rich conditions, where $\mathrm{NO}_{3}^{-}$concentrations are less sensitive to $\mathrm{NH}_{3}$ emissions increases. The response of $\mathrm{NO}_{3}^{-}$concentrations to pathways of $\mathrm{NO}_{x}$ and $\mathrm{NH}_{3}$ emission changes is depicted in Fig. 5b ( $\mathrm{SO}_{2}$ and VOC emissions are also changing simultaneously with $\mathrm{NO}_{x}$ ). A larger decrease in simulated (from that with no consideration of shutdown influences) than observed $\mathrm{NO}_{3}^{-}$concentrations is associated with the $\mathrm{NO}_{x}$ emission reductions, but the change of $\mathrm{NH}_{3}$ emissions can hardly increase the $\mathrm{NO}_{3}^{-}$concentrations under such strong $\mathrm{NH}_{3}$-rich conditions. Therefore, the model predicted no $\mathrm{NH}_{3}$ changes in 2019 , but very small increases of $\mathrm{NH}_{3}$ emissions $(+2 \%)$ in 2020 due to the increased activities in rural areas, which slightly reduced the $\mathrm{NO}_{3}^{-}$low biases (NMB from $-12 \%$ to $-11 \%)$.

The large reduction in $\mathrm{SO}_{2}$ emissions estimated with the response model during the 2020 shutdown considerably reduced the high biases in simulated $\mathrm{SO}_{2}$ and $\mathrm{SO}_{4}^{2-}$ concentra- tions (Fig. 4d-f). However, the $\mathrm{SO}_{4}^{2-}$ biases are still considerable after the emission adjustment because a large fraction of $\mathrm{SO}_{4}^{2-}$ might come from primary sources, which need further investigation especially for its contribution to $\mathrm{p}-\mathrm{PM}_{2.5}$.

Agreement between the simulated and observed $\mathrm{PM}_{2.5}$ concentrations also improves when accounting for the reductions in primary $\mathrm{PM}_{2.5}$ emissions estimated with the response model in both years (Fig. 4g). Another interesting finding is that the simulated $\mathrm{PM}_{2.5}$ concentrations with consideration of all emission changes due to the shutdown (red line in Fig. $4 \mathrm{~g}$ ) are quite similar to $\mathrm{PM}_{2.5}$ predictions without consideration of the shutdown impacts (black line in Fig. 4g). The same behavior is evident for $\mathrm{O}_{3}$ concentrations (red and black lines in Fig. 4b). As discussed above, the reductions in emissions of multiple species during the shutdown had compensating influences on air quality, and the overall effects of the emission changes on $\mathrm{O}_{3}$ and $\mathrm{PM}_{2.5}$ concentrations were neutralized to a relatively small level.

\subsection{Impacts of individual emission changes from the shutdown on $\mathrm{O}_{3}$ and $\mathrm{PM}_{2.5}$ concentrations}

To further investigate the individual impacts of emission changes of each pollutant on $\mathrm{O}_{3}$ and $\mathrm{PM}_{2.5}$ concentrations, we conducted a sensitivity analysis by sequentially adding each incremental emission change into the model system and then calculating the associated changes in $\mathrm{O}_{3}$ and $\mathrm{PM}_{2.5}$ concentrations. By incrementally adding the impacts of emission changes of five pollutants $\left(\Delta \mathrm{NO}_{x}, \Delta \mathrm{VOC}, \Delta \mathrm{NH}_{3}, \Delta \mathrm{SO}_{2}\right.$ and $\left.\Delta \mathrm{p}-\mathrm{PM}_{2.5}\right)$, the concentrations change from the original simulation, without consideration of shutdown impacts (noted as oSIM, shown as grey bar in Fig. 6), and ultimately 
2019

(a)

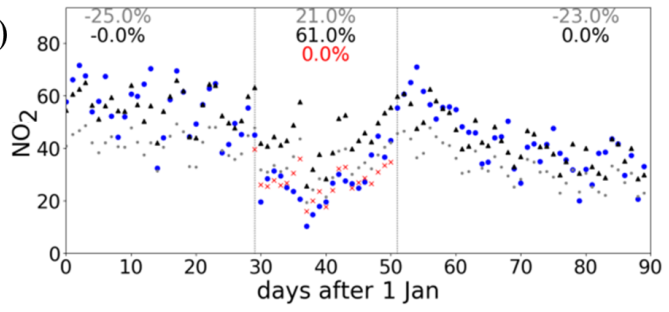

(b)

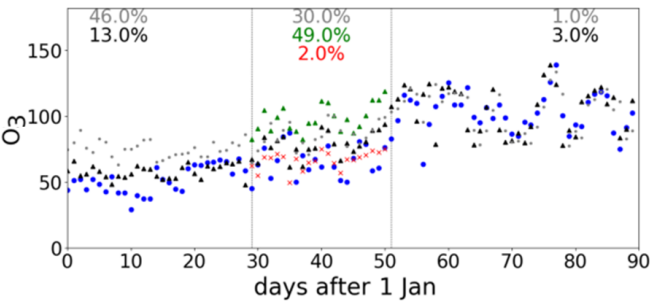

(c)

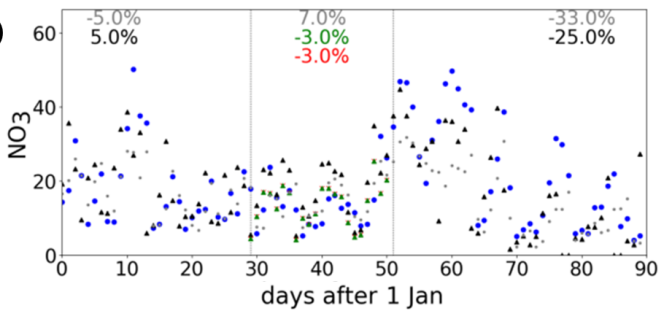

(d)

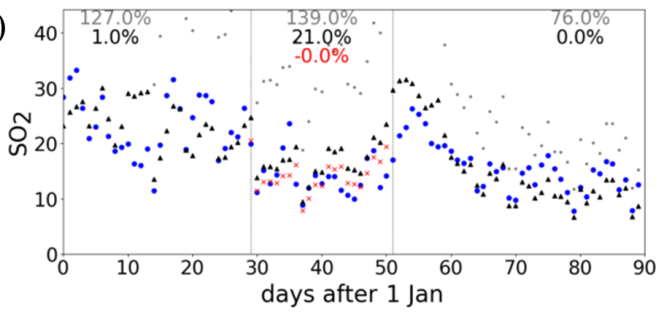

(e)

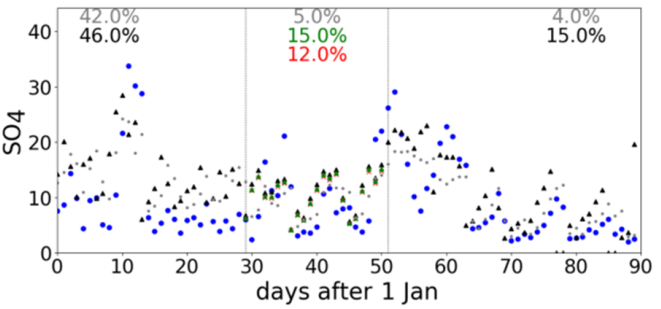

(f)

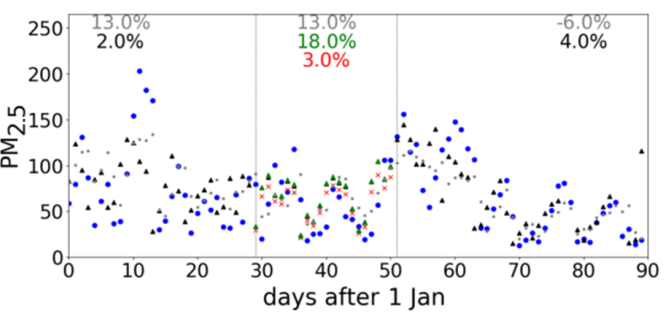

2020
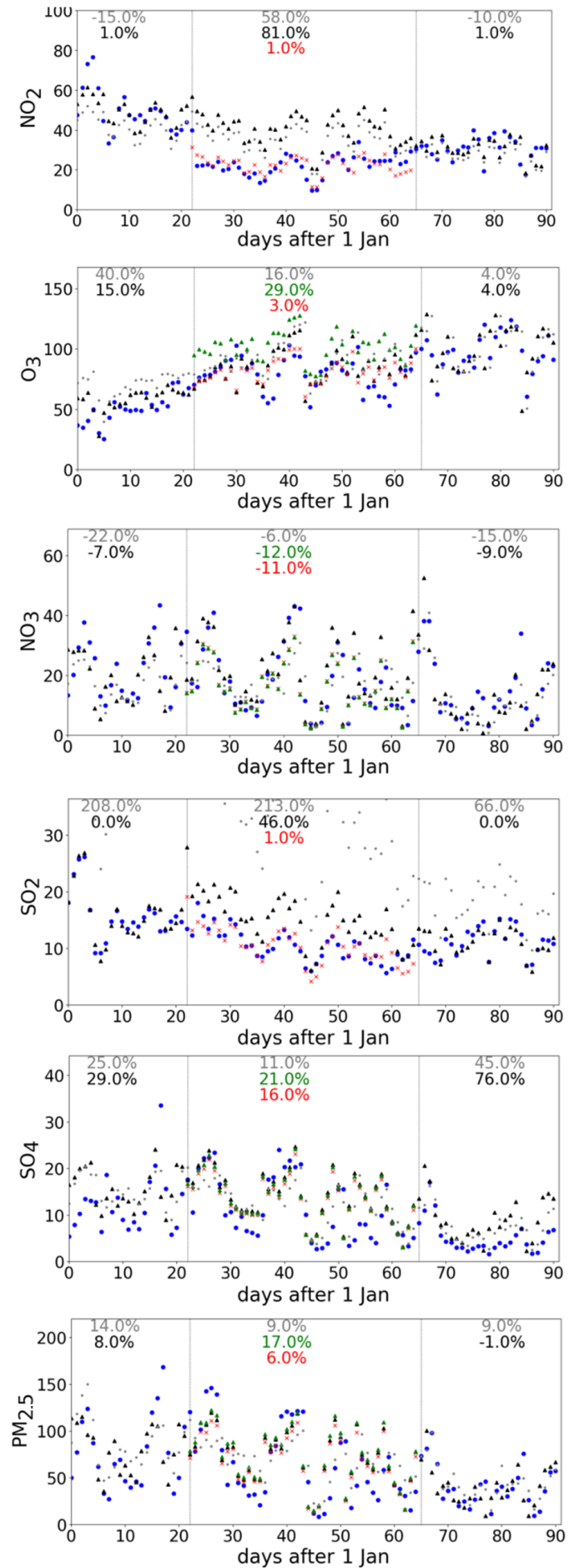

Figure 4. Comparison of the simulated and observed average concentrations on the NCP. The percentage numbers indicate the normalized mean biases in hypothesis and actual simulations respectively for Period 2. Blue dots: observations; black dots: simulations using adjusted emission with no consideration of shutdown influences; red dots: simulations using adjusted emission with consideration of shutdown influences; green dots: simulations using adjusted emission with consideration of shutdown influences without $\mathrm{VOC}$ for $\mathrm{O}_{3}, \mathrm{NH}_{3}$ for $\mathrm{NO}_{3}^{-}$, $\mathrm{SO}_{2}$ for $\mathrm{SO}_{4}^{2-}$, primary $\mathrm{PM}_{2.5}$ for $\mathrm{PM}_{2.5}$; grey dots: original simulations without assimilation; the regional average concentrations were calculated using spatially and temporally matched simulated and observed values; unit: $\mu \mathrm{g} \mathrm{m}{ }^{-3}$. 
(a) $\mathrm{O}_{3}$ to $\mathrm{NO}_{\mathrm{x}}$ (x-axis) and VOC (y-axis)

2019

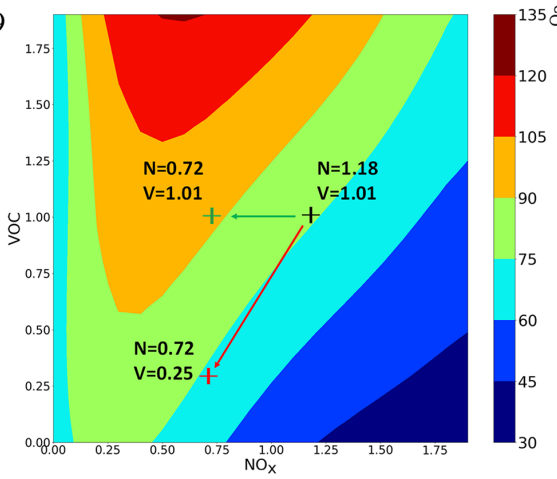

2020

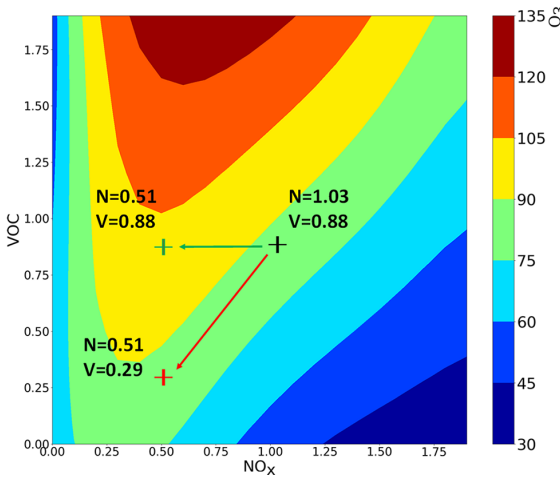

(b) $\mathrm{NO}_{3}{ }^{-}$to $\mathrm{NO}_{\mathrm{x}}$ (x-axis) and $\mathrm{NH}_{3}$ (y-axis)
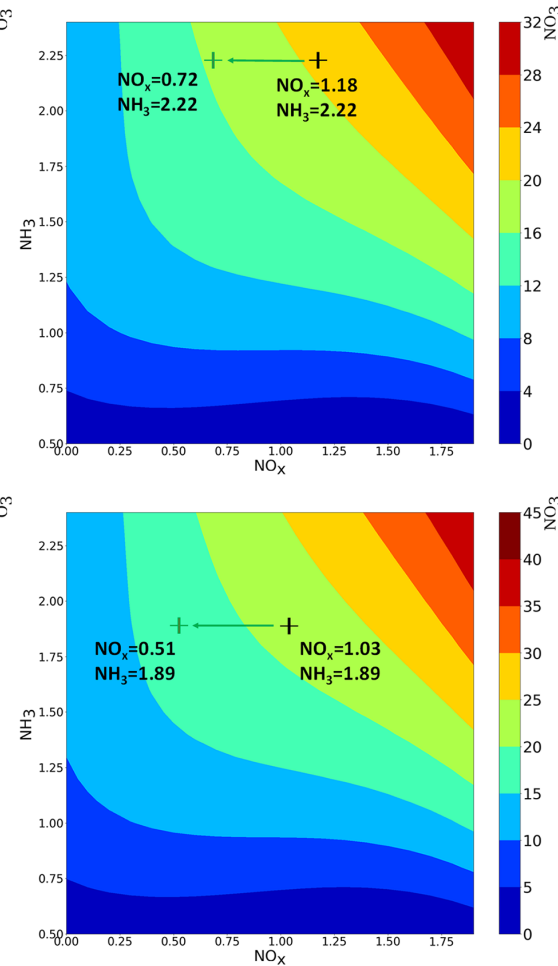

Figure 5. Implication of emission changes from the $\mathrm{O}_{3}$ and $\mathrm{NO}_{3}^{-}$response isopleths during shutdowns. The axes indicate emission ratios relative to the prior emissions; black symbol: adjusted emission ratios with no consideration of shutdown; red symbol: adjusted emission ratios with consideration of shutdown; green symbol: adjusted emission ratios without considering simultaneous $\mathrm{VOC}$ changes for $\mathrm{O}_{3}$, and $\mathrm{NH}_{3}$ changes for $\mathrm{NO}_{3}$; background color: $\mathrm{O}_{3}$ and $\mathrm{NO}_{3}^{-}$concentrations, $\mu \mathrm{g} \mathrm{m}{ }^{-3}$.

reaching observed levels (noted as OBS, shown as narrow blue bars in Fig. 6). One thing that should be noted is that we scaled the individual impact of emission changes based on the ratio of observation to the adjusted simulation after considering overall impacts, to eliminate the small discrepancy between the observations and the adjusted simulations after considering the overall impacts. Therefore, the overall changes in concentrations due to the shutdown can be reflected by the difference between the observation (OBS) and simulation with no consideration of shutdown (oSIM).

For $\mathrm{O}_{3}$, the reduction of $\mathrm{NO}_{x}$ emissions leads to a significant enhancement of $\mathrm{O}_{3}$ (see $\Delta \mathrm{NO}_{x}$ ) due to the VOClimited regime in winter (Xing et al., 2019), while such an $\mathrm{O}_{3}$ enhancement has been largely or completely mitigated thanks to the simultaneous reduction of VOC emissions (see $\triangle$ VOC) in both 2019 and 2020. This behavior is particularly evident in Henan and Shandong provinces, which experienced substantial VOC reductions during the shutdown (Table 3). Such benefits from simultaneous VOC controls also occurred for $\mathrm{PM}_{2.5}$ concentrations. Compared with $\mathrm{O}_{3}$, the changes in $\mathrm{PM}_{2.5}$ concentrations are more complex to interpret due to the influence of emission changes for $\mathrm{SO}_{2}$ $\left(\Delta \mathrm{SO}_{2}\right), \mathrm{NH}_{3}\left(\Delta \mathrm{NH}_{3}\right)$ and $\mathrm{p}-\mathrm{PM}_{2.5}\left(\Delta \mathrm{p}-\mathrm{PM}_{2.5}\right)$ in addi- tion to $\mathrm{NO}_{x}$ and VOC. Results suggest that the reductions of $\mathrm{p}-\mathrm{PM}_{2.5}$ emissions tended to favor $\mathrm{PM}_{2.5}$ decreases, while the $\Delta \mathrm{SO}_{2}$ and $\Delta \mathrm{NH}_{3}$ emission changes have negligible influence. Overall, reductions in p-PM $\mathrm{PM}_{2.5}$ and VOC emissions helped mitigate potential $\mathrm{PM}_{2.5}$ concentration enhancements in most NCP provinces. Similar findings are suggested in Hang et al. (2020), who observed enhanced secondary pollution during the COVID-19 period. The air quality impacts from the unexpected controls during the COVID-19 shutdown suggest that strengthened controls on $\mathrm{p}-\mathrm{PM}_{2.5}$ emissions and well-balanced reductions in $\mathrm{NO}_{x}$ and VOC emissions would be an effective strategy for further improving air quality on the NCP (Xing et al., 2018).

\section{Summary and conclusion}

In summary, this study developed a response-based inversion modeling framework and applied it to characterize the emission changes and associated air quality impacts during the 2019 Spring Festival and the 2020 COVID-19 pandemic shutdown. Our results indicate that the response model can effectively adjust the assumed prior emissions such that air quality predictions match well with observed concentrations. 

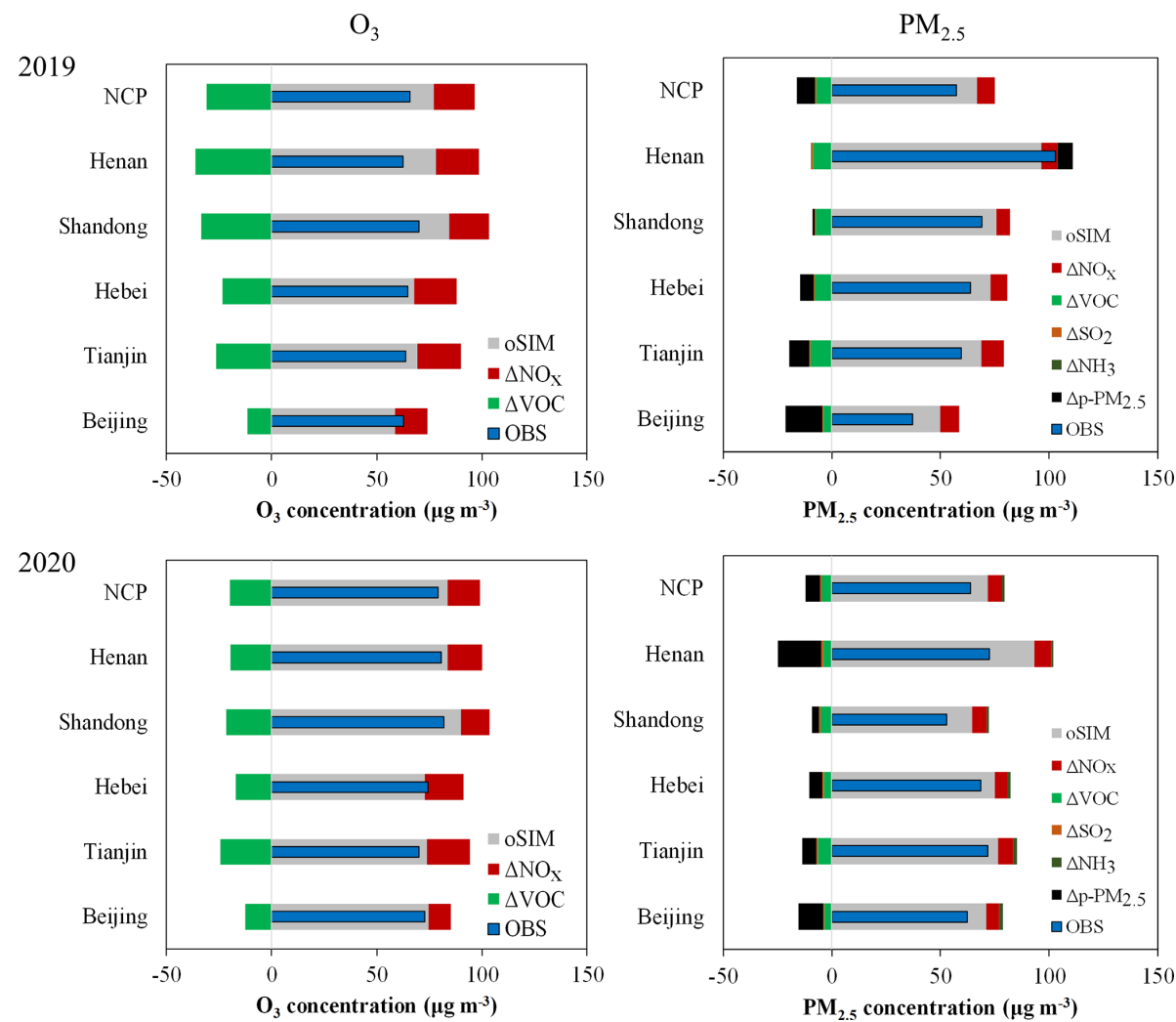

Figure 6. Contributions to the changes of $\mathrm{O}_{3}$ and $\mathrm{PM}_{2.5}$ concentrations during Period 2. OBS: observation; oSIM: no consideration of shutdown; $\Delta \mathrm{NO}_{x}$ : impacts due to the change of $\mathrm{NO}_{x}$ emissions; $\triangle \mathrm{VOC}$ : impacts due to the change of VOC emissions; $\Delta \mathrm{NH}_{3}$ : impacts due to the change of $\mathrm{NH}_{3}$ emissions; $\Delta \mathrm{SO}_{2}$ : impacts due to the change of $\mathrm{SO}_{2}$ emissions; $\Delta \mathrm{p}-\mathrm{PM}_{2.5}$ : impacts due to the change of primary $\mathrm{PM}_{2.5}$ emissions.

The model also captures the temporal variations of emissions associated with changes in meteorological conditions. The model may suffer some uncertainties from deficiencies in model chemical mechanisms (e.g., conversion of $\mathrm{SO}_{2}$ to $\mathrm{SO}_{4}^{2-}$ ), as well as the quality of prior emissions and limited coverage of observations. Difficulties are also found in estimating the $\mathrm{NH}_{3}$ emission changes under strong $\mathrm{NH}_{3}$-rich conditions by using the current inversion method based on the concentration of PM chemical components. However, with the continued growth in observational datasets from both surface monitors and satellite retrievals, improvements in knowledge of atmospheric science and development of advanced assimilation technologies, the new response-based inversion model has great potential to further improve the accuracy and efficiency of emission inventory updates. The importance of reliable bottom-up inventories for defining prior emissions by sector, combined with the ability of the topdown inversion model to rapidly adjust emissions for consistency with observations, demonstrates how bottom-up and top-down emissions modeling methods are complementary.

The response model was applied to the investigation of emission changes during the COVID-19 shutdown. The emission changes were estimated by comparing emissions for actual conditions with emissions for hypothetical conditions assuming that the shutdown did not occur. Emission levels during the COVID-19 shutdown period were estimated by applying the temporal profiles of sectoral emissions from the bottom-up inventory. These estimates may suffer some uncertainties associated with the temporal profiles and the assumption of no shutdown impacts during the post-shutdown period. Our results suggest that the shutdowns in 2019 and 2020 had considerable impacts on air pollutant emissions. Longer and stronger impacts are found in 2020 due to the COVID-19 pandemic compared to the Spring Festival of the previous year. The anthropogenic emissions of $\mathrm{NO}_{2}, \mathrm{SO}_{2}$, VOC and primary $\mathrm{PM}_{2.5}$ on the NCP were reduced by $51 \%$, $28 \%, 67 \%$ and $63 \%$, respectively, due to the COVID-19 shutdown in 2020 . The estimated ratio might be slightly underestimated considering the lag effects after the COVID-19 shutdown. We also found that emission changes associated with the shutdown periods had limited impacts on surface $\mathrm{O}_{3}$ and $\mathrm{PM}_{2.5}$ concentrations due to compensating effects of emission changes in different pollutants. Based on our analysis, careful controls on $\mathrm{NO}_{x}$ emission sources on the NCP are recommended in combination with simultaneous controls on VOC and $\mathrm{NH}_{3}$ sources. Such a comprehensive strategy 
would minimize the potential negative impacts on air quality of $\mathrm{NO}_{x}$ emission reductions during VOC-limited conditions in winter. This study also illustrates that air quality improvements do not necessary follow from precursor emission reductions, and multi-pollutant nonlinear response models are therefore critical tools for representing the nonlinear relationship between emissions and concentrations in designing effective control strategies.

Code availability. The original data and code used in this study are available upon request from the corresponding authors.

Supplement. The supplement related to this article is available online at: https://doi.org/10.5194/acp-20-14347-2020-supplement.

Author contributions. JX and SL designed the methodology, conducted the analysis and wrote the original draft. YJ conducted the WRF-CMAQ simulation. SW, DD, ZD and JH helped with the bottom-up emission inventory. YZ helped with the RSM model. All authors contributed to writing the paper.

Competing interests. The authors declare that they have no conflict of interest.

Acknowledgements. This work was completed on the "Explorer 100" cluster system of Tsinghua National Laboratory for Information Science and Technology. We thank Carey Jang, James Kelly, Jian Gao and Jingnan $\mathrm{Hu}$ for contributions to the study. The authors gratefully acknowledge the free availability and use of observation datasets.

Financial support. This research has been supported by the National Key R \& D program of China (grant no. 2018YFC0213805) and the National Natural Science Foundation of China (grant nos. 21625701 and 41907190).

Review statement. This paper was edited by Tim Butler and reviewed by two anonymous referees.

\section{References}

Cao, H., Fu, T.-M., Zhang, L., Henze, D. K., Miller, C. C., Lerot, C., Abad, G. G., De Smedt, I., Zhang, Q., van Roozendael, M., Hendrick, F., Chance, K., Li, J., Zheng, J., and Zhao, Y.: Adjoint inversion of Chinese non-methane volatile organic compound emissions using space-based observations of formaldehyde and glyoxal, Atmos. Chem. Phys., 18, 15017-15046, https://doi.org/10.5194/acp-18-15017-2018, 2018.
Ding, D., Xing, J., Wang, S., Liu, K., and Hao, J.: Estimated contributions of emissions controls, meteorological factors, population growth, and changes in baseline mortality to reductions in ambient $\mathrm{PM}_{2.5}$ and $\mathrm{PM}_{2.5}$-related mortality in China, 2013-2017, Environ. Health Persp., 127, 067009, https://doi.org/10.1289/EHP4157, 2019.

Hartley, D. and Prinn, R.: Feasibility of determining surface emissions of trace gases using an inverse method in a threedimensional chemical transport model, J. Geophys. Res.-Atmos., 98, 5183-5197, 1993.

Huang, X., Ding, A., Gao, J., Zheng, B., Zhou, D., Qi, X., Tang, R., Wang, J., Ren, C., Nie, W., Chi, X., Xu, Z., Chen, L., Li, Y., Che, F., Pan, N., Wang, H., Tong, D., Qin, W., Cheng, W., Liu, W., Fu, Q., Liu, B., Chai, F., Davis, S. J., Zhang, Q., and He, K.: Enhanced secondary pollution offset reduction of primary emissions during covid-19 lockdown in china, National Science Review, nwaa137, https://doi.org/10.1093/nsr/nwaa137, 2020.

Li, L., Li, Q., Huang, L., Wang, Q., Zhu, A., Xu, J., Liu, Z., Li, H., Shi, L., Li, R., and Azari, M.: Air quality changes during the COVID-19 lockdown over the Yangtze River Delta Region: An insight into the impact of human activity pattern changes on air pollution variation, Sci. Total Environ., 732, 139282 https://doi.org/10.1016/j.scitotenv.2020.139282, 2020.

Li, M., Zhang, Q., Kurokawa, J.-I., Woo, J.-H., He, K., Lu, Z., Ohara, T., Song, Y., Streets, D. G., Carmichael, G. R., Cheng, Y., Hong, C., Huo, H., Jiang, X., Kang, S., Liu, F., Su, H., and Zheng, B.: MIX: a mosaic Asian anthropogenic emission inventory under the international collaboration framework of the MICS-Asia and HTAP, Atmos. Chem. Phys., 17, 935-963, https://doi.org/10.5194/acp-17-935-2017, 2017.

Lu, Z., Streets, D. G., de Foy, B., Lamsal, L. N., Duncan, B. N., and Xing, J.: Emissions of nitrogen oxides from US urban areas: estimation from Ozone Monitoring Instrument retrievals for 2005-2014, Atmos. Chem. Phys., 15, 10367-10383, https://doi.org/10.5194/acp-15-10367-2015, 2015.

Mendoza-Dominguez, A. and Russell, A. G.: Iterative inverse modeling and direct sensitivity analysis of a photochemical air quality model, Environ. Sci. Technol,, 34, 4974-4981, 2000.

Miyazaki, K., Eskes, H., Sudo, K., Boersma, K. F., Bowman, K., and Kanaya, Y.: Decadal changes in global surface $\mathrm{NO}_{x}$ emissions from multi-constituent satellite data assimilation, Atmos. Chem. Phys., 17, 807-837, https://doi.org/10.5194/acp-17-8072017, 2017.

Napelenok, S. L., Pinder, R. W., Gilliland, A. B., and Martin, R. $\mathrm{V}$.: A method for evaluating spatially-resolved $\mathrm{NO}_{x}$ emissions using Kalman filter inversion, direct sensitivities, and spacebased $\mathrm{NO}_{2}$ observations, Atmos. Chem. Phys., 8, 5603-5614, https://doi.org/10.5194/acp-8-5603-2008, 2008.

Shi, X. and Brasseur, G. P.: The Response in Air Quality to the Reduction of Chinese Economic Activities during the COVID-19 Outbreak, Geophys. Res. Lett., 47, e2020GL088070, https://doi.org/10.1029/2020GL088070, 2020.

Tang, W., Cohan, D. S., Lamsal, L. N., Xiao, X., and Zhou, W.: Inverse modeling of Texas $\mathrm{NO}_{x}$ emissions using spacebased and ground-based NO2 observations, Atmos. Chem. Phys., 13, 11005-11018, https://doi.org/10.5194/acp-13-11005-2013, 2013.

Tang, W., Arellano, A. F., Gaubert, B., Miyazaki, K., and Worden, H. M.: Satellite data reveal a common combustion emission path- 
way for major cities in China, Atmos. Chem. Phys., 19, 42694288, https://doi.org/10.5194/acp-19-4269-2019, 2019.

Wang, P., Chen, K., Zhu, S., Wang, P., and Zhang, H.: Severe air pollution events not avoided by reduced anthropogenic activities during COVID-19 outbreak, Resour. Conserv. Recy., 158, 104814, https://doi.org/10.1016/j.resconrec.2020.104814, 2020.

Wang, Q. and Su, M.: A preliminary assessment of the impact of COVID-19 on environment - A case study of China, Sci. Total Environ., 728, 138915, https://doi.org/10.1016/j.scitotenv.2020.138915, 2020.

Wang, S., Zhao, M., Xing, J., Wu, Y., Zhou, Y., Lei, Y., He, K., Fu, L., and Hao, J.: Quantifying the air pollutants emission reduction during the 2008 Olympic Games in Beijing, Environ. Sci. Technol., 44, 2490-2496, 2010.

Wang, S., Xing, J., Chatani, S., Hao, J., Klimont, Z., Cofala, J., and Amann, M.: Verification of anthropogenic emissions of China by satellite and ground observations, Atmos. Environ., 45, 63476358, 2011a.

Wang, S., Xing, J., Jang, C., Zhu, Y., Fu, J. S., and Hao, J.: Impact assessment of ammonia emissions on inorganic aerosols in East China using response surface modeling technique, Environ. Sci. Technol., 45, 9293-9300, 2011b.

Xing, J., Wang, S. X., Jang, C., Zhu, Y., and Hao, J. M.: Nonlinear response of ozone to precursor emission changes in China: a modeling study using response surface methodology, Atmos. Chem. Phys., 11, 5027-5044, https://doi.org/10.5194/acp-115027-2011, 2011.

Xing, J., Pleim, J., Mathur, R., Pouliot, G., Hogrefe, C., Gan, C.-M., and Wei, C.: Historical gaseous and primary aerosol emissions in the United States from 1990 to 2010, Atmos. Chem. Phys., 13, 7531-7549, https://doi.org/10.5194/acp-13-7531-2013, 2013.

Xing, J., Wang, S., Zhao, B., Wu, W., Ding, D., Jang, C., Zhu, Y., Chang, X., Wang, J., Zhang, F., and Hao, J.: Quantifying nonlinear multiregional contributions to ozone and fine particles using an updated response surface modeling technique, Environ. Sci. Technol., 51, 11788-11798, 2017.
Xing, J., Ding, D., Wang, S., Zhao, B., Jang, C., Wu, W., Zhang, F., Zhu, Y., and Hao, J.: Quantification of the enhanced effectiveness of $\mathrm{NO}_{x}$ control from simultaneous reductions of VOC and $\mathrm{NH}_{3}$ for reducing air pollution in the Beijing-TianjinHebei region, China, Atmos. Chem. Phys., 18, 7799-7814, https://doi.org/10.5194/acp-18-7799-2018, 2018.

Xing, J., Ding, D., Wang, S., Dong, Z., Kelly, J. T., Jang, C., Zhu, Y., and Hao, J.: Development and application of observable response indicators for design of an effective ozone and fine-particle pollution control strategy in China, Atmos. Chem. Phys., 19, 13627 13646, https://doi.org/10.5194/acp-19-13627-2019, 2019.

Xing, J., Li, S., Ding, D., Kelly, J.T., Wang, S., Jang, C., Zhu, Y., and Hao, J. M.: Data assimilation of ambient concentrations of multiple air pollutants using an emission-concentration response modeling framework, Atmosphere, in press, 2020a.

Xing, J., Zheng, S., Ding, D., Kelly, J. T., Wang, S., Li, S., Qin, T., Ma, M., Dong, Z., Jang, C., and Zhu, Y.: Deep learning for prediction of the air quality response to emission changes, Environ. Sci. Technol., 54, 8589-8600, 2020 b.

Zhang, L., Chen, Y., Zhao, Y., Henze, D. K., Zhu, L., Song, Y., Paulot, F., Liu, X., Pan, Y., Lin, Y., and Huang, B.: Agricultural ammonia emissions in China: reconciling bottom-up and top-down estimates, Atmos. Chem. Phys., 18, 339-355, https://doi.org/10.5194/acp-18-339-2018, 2018.

Zhang, S., Xing, J., Sarwar, G., Ge, Y., He, H., Duan, F., Zhao, Y., He, K., Zhu, L., and Chu, B.: Parameterization of heterogeneous reaction of $\mathrm{SO}_{2}$ to sulfate on dust with coexistence of $\mathrm{NH}_{3}$ and $\mathrm{NO}_{2}$ under different humidity conditions, Atmos. Environ., 208, 133-140, 2019. 